\title{
Psychiatric morbidity in prisoners with intellectual disabilities: analysis of prison survey data for England and Wales
}

Angela Hassiotis, Dina Gazizova, Leah Akinlonu, Paul Bebbington, Howard Meltzer and Andre Strydom

\author{
Summary \\ A substantial number of prisoners have intellectual \\ disabilities. We analysed data on a sample drawn from al \\ prisons in England and Wales. Intellectual disability was \\ defined as Quick Test scores equivalent to an IQ of $\leqslant 65$. \\ We found a significantly higher prevalence of probable \\ psychosis, attempted suicide and cannabis use in \\ prisoners with intellectual disabilities. Presence of \\ intellectual disability was twice as likely to be associated
}

with probable psychosis but the relationship was fully mediated by self-rated health status. It is important to identify this group as early as possible in order to provide timely interventions to cope in adverse environments and manage substance misuse.

\section{Declaration of interest}

None.
Estimated rates of intellectual disability in prisoners range from $0.5 \%$ to $1.5 \%$, with upper estimates of up to $13 \%{ }^{1-3}$ depending on methods of ascertainment. The considerable needs of prisoners with intellectual disabilities in Britain have been highlighted by the Bradley report, ${ }^{4}$ which recommended early identification and needs assessment, in order to inform how and where they would be most appropriately treated. Our aim was to examine the prevalence of intellectual disability in a British sample of prisoners and its association with mental disorders. We hypothesised that psychiatric morbidity in prisoners with intellectual disabilities would be increased. We also investigated the correlates of increased psychiatric morbidity in this subset of prisoners.

\section{Method}

We drew our data from a national two-stage survey in which a random sample of 3563 prisoners was selected from all 131 prisons (total of 61944 prisoners) in England and Wales (1 in 8 males in remand, 1 in 34 sentenced males, and 1 in 3 of all female prisoners)..$^{5}$ Of this sample, $3142(88 \%)$ prisoners gave informed consent to be interviewed. Trained lay interviewers collected information about sociodemographic status, general health, selfharm, drug and alcohol misuse, key life events, post-traumatic stress, difficulties with daily living, history of previous convictions, use of services in prison and lifetime experience of services. The Clinical Interview Schedule - Revised (CIS-R) was used to establish the presence of common mental disorders. An overall category of 'probable psychosis' was used comprising those identified by the Schedules for Clinical Assessment in Neuropsychiatry (SCAN), together with those who did not have a phase-two interview but had endorsed two or more criteria on the Psychosis Screening Questionnaire in the first-phase interview. Personality disorders were assessed by the self-administered Structured Clinical Interview for DSM-IV-TR Axis II Personality Disorders (SCID-II) interview. The Quick Test measured participants' intellectual functioning. This correlates well with the Wechsler Adult Intelligence Scale - Revised (WAIS-R) Full Scale IQ. ${ }^{6}$ It is only valid for first-language English speakers, so 375 participants born outside of the UK and Ireland were excluded from this subsample. Intellectual disability was defined by a score of 25 or less on the Quick Test (equivalent to an IQ of $\leqslant 65$ ), together with limited educational attainment (i.e. not higher than a GCSE or O-Level qualification). Any participants who had a Quick Test score of $<25$ but reported educational attainment higher than O-Level were included in the normal ability group.

The 'survey' commands in STATA 11.0 for Windows were used for our analyses as they provide robust estimates of variance in complex data-sets. The data were weighted to adjust for the differential sampling fractions by type of prisoner (remand or sentenced, male or female) and for non-response within each group.

We used logistic regression to explore the association between intellectual disability and psychiatric disorder, sequentially adjusting for sociodemographic variables (age, gender, ethnicity, in care as a child), clinical attributes (cannabis dependence, self-rated health status) and sentence type and length by calculating odds ratios.

\section{Results}

Four per cent $(n=170)$ of the sample had intellectual disabilities. Prisoners with intellectual disabilities were more likely to be female, younger than 30 years $(79.7 \% v .61 \%, P<0.001)$ and from Black and minority ethnic groups $(16.2 \% v .12 .4 \%, P=0.05)$. A greater proportion had been in Local Authority care as children (42\% v. $29 \%, P=0.009$ ) and had been admitted to a mental hospital (15.6\% v. $8.8 \%, P=0.02)$ (online Table DS1).

A greater proportion of prisoners with intellectual disabilities were on remand $(33 \%$ v. $19.4 \%, P<0.001)$ or had shorter sentences (up to 12 months; $83.9 \%$ v. 66.7\%, $P=0.004$ ). Although similar proportions of prisoners with and without intellectual disabilities had been given a court order for psychiatric care, those with intellectual disabilities were more likely to be currently located in a setting other than a 'normal prison unit', such as the hospital wing of the prison $(10.7 \% v .6 . \%, P<0.001)$ (online Table DS2).

Although they appeared to have similar levels of visits from family or friends, inmates with intellectual disabilities were more likely to report feeling a moderate to severe lack of social support (71.4\% v. 58.2\%, $P=0.05$ ) (online Table DS3).

Overall, $12.6 \%$ of prisoners with intellectual disabilities rated their general health as 'very bad', compared with $6.3 \%$ of those without intellectual disabilities $(P<0.001)$. Prisoners with intellectual disabilities were twice as likely to have had probable 
psychosis $(11.3 \%$ v. $5.7 \%, P<0.01)$. Common mental disorders were somewhat more prevalent (CIS-R score $>12$ ) among prisoners with intellectual disabilities $(53.1 \%$ v. $43.6 \%, P=0.08)$. We found a twofold increase in attempted suicide in prisoners with intellectual disabilities $(13.5 \%$ v. $6.5 \%, P=0.02)$, and relatively higher rates of history of self-harm $(19.9 \% v .13 .8 \%$, $P=0.07)$. Although lifetime drug use and alcohol dependence were similar in both prisoner groups, more prisoners with intellectual disabilities were cannabis dependent/frequent users (51.2\% v. 42.1\%, $P=0.01$ ). Fewer prisoners with intellectual disabilities received treatment for drug addiction while in prison and a significantly smaller proportion had any drug education (11.5\% v. 22.1\%, $P=0.01$ ) (online Table DS4). Before adjustment, there was no significant association between common mental disorders and intellectual disabilities $(\mathrm{OR}=0.68,95 \%$ CI $0.44-$ 1.05). The presence of intellectual disability, however, predicted the presence of probable psychosis $(\mathrm{OR}=2.08,95 \%$ CI $1.16-$ $3.75 ; P=0.014)$. Introduction of sociodemographic variables (age, gender, ethnicity) to the model did not alter the relationship ( $\mathrm{OR}=2.25,95 \%$ CI 1.23-4.09; $P=0.008$ ), neither did being in care as a child, or length of imprisonment. Adding cannabis dependence mediated the strength of association between probable psychosis and intellectual disability $(\mathrm{OR}=1.99,95 \% \mathrm{CI}$ 1.04-3.78; $P=0.03$ ). However, the inclusion of self-rated health status (poor) appeared to fully mediate the relationship $(\mathrm{OR}=1.65,95 \%$ CI $0.88-3.09 ; P=0.12)$ (Table 1$)$.

\section{Discussion}

The national prisons survey ${ }^{5}$ remains the 'most influential and comprehensive"7 recent survey of the mental health of prisoners. It shows a higher prevalence of people with intellectual disabilities than previously reported. ${ }^{4}$ To compensate for the lack of current norms for the Quick Test, we used a lower IQ equivalence threshold but we may still have overestimated the true prevalence of intellectual disability in the prison population. Underestimation is also possible. Owing to the exclusion of individuals born outside the UK and Ireland, our findings are not representative of all prisoners.

The excess of psychosis may pre-exist imprisonment but it might also be due to onset during incarceration as prisoners are challenged by the stressful and complex prison environment. The association between intellectual disability and psychosis was fully mediated by self-reported health status, but not by other factors. This may mean that participants with intellectual disabilities rate themselves as having particularly poor health in

\begin{tabular}{|c|c|c|}
\hline & \multicolumn{2}{|c|}{ Presence of psychosis } \\
\hline Variables in equation & $\begin{array}{c}\text { Odds ratio }(95 \% \mathrm{Cl}) \text { for group } \\
\text { with ID v. normal IQ }\end{array}$ & $P$ \\
\hline ID only & $2.08(1.16-3.75)$ & 0.014 \\
\hline $\begin{array}{l}\text { ID + age, gender, ethnicity, } \\
+ \text { in care as a child }\end{array}$ & $2.09(1.15-3.19)$ & 0.015 \\
\hline $\begin{array}{l}\text { ID + age, gender, ethnicity, } \\
\text { + length of sentence }\end{array}$ & $2.25(1.23-4.12)$ & 0.009 \\
\hline $\begin{array}{l}\text { ID + age, gender, ethnicity, } \\
\text { + cannabis dependence }\end{array}$ & $1.99(1.04-3.78)$ & 0.036 \\
\hline $\begin{array}{l}\text { ID + age, gender, ethnicity, } \\
\text { + self-rated health status }\end{array}$ & $1.65(0.88-3.09)$ & 0.12 \\
\hline
\end{tabular}

the context of suffering from psychosis, or that poorer physical health is coexisting with psychosis in this group. ${ }^{8}$

Increased prevalence of suicidal behaviour in prison has been reported elsewhere. ${ }^{9}$

The higher proportion of prisoners with intellectual disabilities on remand suggests that the current procedures may be partially effective in diverting prisoners with intellectual disabilities away from custodial sentences by transferring them elsewhere prior to sentencing, ${ }^{10}$ although poor identification of such prisoners may be an ongoing problem. ${ }^{11}$ Furthermore, prisoners with intellectual disabilities may learn to hide their cognitive limitations, for fear of discrimination. ${ }^{12}$ Reduced likelihood of educational interventions about substance misuse while in prison may be an indication of exclusion or shortage of specialist input.

Given the highly burdened prison system, we question whether the care that such vulnerable prisoners receive is adequate or suited to their needs.

\footnotetext{
Angela Hassiotis, PhD, FRCPsych, Department of Mental Health Sciences, University College London Medical School; Dina Gazizova, MRCPsych, Central \& North West London NHS Foundation Trust, The Riverside Centre, Hillingdon Hospital, Uxbridge, Middlesex; Leah Akinlonu, MRCPsych, Hertfordshire Partnership NHS Foundation Trust, Eric Shepherd Unit, Abbots Langley; Paul Bebbington, PhD, FRCPsych, Department of Mental Health Sciences, University College London Medical School; Howard Meltzer, PhD, Department of Health Sciences, College of Medicine, Biological Sciences and Psychology, University of Leicester; Andre Strydom, PhD, MRCPsych, Department of Mental Health Sciences, University College London Medical School, UK

Correspondence: Angela Hassiotis, Department of Mental Health Sciences, University College London Medical School, Charles Bell House, 67-73 Riding House Street, London W1W 7EY, UK. Email: a.hassiotis@ucl.ac.uk

First received 4 Oct 2010, final revision 10 Jan 2010, accepted 23 Feb 2011
}

\section{References}

1 Barron P, Hassiotis A, Banes J. Offenders with intellectual disability: the size of the problem and therapeutic outcomes. J Intellec Disabil Res 2002; 6: 454-63.

2 Fazel S, Xenitidis K, Powell J. The prevalence of intellectual disabilities among 12000 prisoners - a systematic review. Int J Law Psychiatry 2008; 31 : 369-73.

3 Herrington V. Assessing the prevalence of intellectual disability among young male prisoners. J Intellec Disabil Res 2009; 53: 397-410.

4 Department of Health. The Bradley Report. Lord Bradley's Review of People with Mental Health Problems or Learning Disabilities in the Criminal Justice System. TSO (The Stationery Office), 2009.

5 Singleton N, Meltzer H, Gatward R, Coid J, Deasy D. Psychiatric Morbidity among Prisoners in England and Wales: A Survey Carried out in 1997 by the Social Survey Division of ONS on Behalf of the Department of Health. HMSO, 1998.

6 Wechsler D. Wechsler Adult Intelligence Scale - Revised. Psychological Corporation, 1981.

7 Brooker C, Gojkovic D, Siridfield C, Fox C. Lord Bradley's review of people with mental health or learning disabilities in the criminal justice system in England. All not equal in the eyes of the law? Int J Prison Health 2010; 5: $171-5$.

8 Osborn DPJ, Levy G, Nazareth I, Petersen I, Islam A, King MB. Relative risk of cardiovascular and cancer mortality in people with severe mental illness from the United Kingdom's general practice research database. Arch Gen Psychiatry 2007; 64: 242-9.

9 Jenkins R, Bhugra $D$, Meltzer $H$, Singleton $N$, Bebbington $P$, Brugha $T$, et al. Psychiatric and social aspects of suicidal behaviour in prisons. Psychol Med 2005; 35: 257-69.

10 Royal College of Psychiatrists. Prison Psychiatry: Adult Prisons in England and Wales (College Report CR141). Royal College of Psychiatrists, 2007.

11 Sondenaa E, Rasmussen K, Palmstierna T, Nottestad J. The prevalence and nature of intellectual disability in Norwegian prisons. I Intellec Disabil Res 2008; 52: 1129-37.

12 Talbot J. No One Knows: Report and Final Recommendations. Prisoners' Voices: Experiences of the Criminal Justice System by Prisoners with Learning Disabilities and Difficulties. Prison Reform Trust, 2008. 